\title{
Pemilihan Peserta Lomba Kompetensi Siswa Menggunakan Metode TOPSIS
}

\author{
Maulia Rahman ${ }^{1,}$ Jufriadi Na'am $^{2}$, Julius Santony ${ }^{3}$ \\ ${ }^{1}$ Universitas Potensi Utama, Medan \\ ${ }^{2,3}$ Fakultas Ilmu Komputer, Universitas Putra Indonesia YPTK

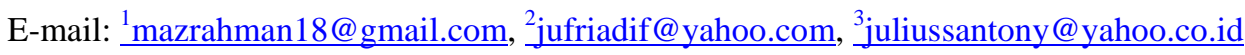

\begin{abstract}
Vocational High School Student Competency Competition (Vocational School LKS) is a series of activities conducted by the Education Office. This activity is carried out as one of the means and ways to measure the success of the education process in Vocational Schools. LKS is held as a vehicle for competition in promoting students' abilities to the business world and industry. For the determination of the winning contestants correctly and precisely requires a good decision system. The method that used in this study is TOPSIS on report card grades in 2018. The results of this study are participants who qualify with a value of $V=0.7978$. Participants who qualify for this place rank first in the match with $80 \%$ conformity to the participants sent in the match. So that this method is a recommendation to dismiss the process of determining the next LKS contest participant.
\end{abstract}

Keyword: LKS, Determination of Participants, Ranking, DSS, TOPSIS

\begin{abstract}
Abstrak
Lomba Kompetensi Siswa Sekolah Menengah Kejuruan (LKS SMK) merupakan serangkaian kegiatan yang diselengggarakan oleh Dinas Pendidikan. Kegiatan ini dilakukan sebagai salah satu sarana dan cara untuk mengukur keberhasilan proses pendidikan di SMK. LKS diselenggarakan sebagai wahana kompetisi dalam mempromosikan kemampuan siswa kepada dunia usaha dan industri. Untuk penentuan peserta lomba yang menang secara tepat dan tepat membutuhkan suatu sistem keputusan yang baik. Metode yang dipakai dalam penelitian ini adalah TOPSIS terhadap data nilai raport tahun 2018. Hasil dari penelitian ini adalah peserta yang lolos adalah dengan nilai $\mathrm{V}=0.7978$. Peserta yang lolos ini menempati urutan pernagkingan pertama dengan kesesuain $80 \%$ terhadap peserta yang diutus dalam pertandingan tersebut. Sehingga metode ini menjadi rekomendasi untuk memperpecat proses penentuaan peserta lomba LKS selanjutnya.
\end{abstract}

Kata kunci: LKS, Penetapan peserta, Perangkingan, SPK, TOPSIS

\section{Pendahuluan}

Pada pasal 26, ayat 3 PP 19 Tahun 2005, Sekolah Menengah Kejuruan (SMK) diselenggarakan dengan tujuan untuk meningkatkan kecerdasan, pengetahuan, kepribadian, ahklak mulia, serta keterampilan untuk hidup mandiri dan mengikuti pendidikan lebih lanjut sesuai dengan kejuruannya [1]. Berdasarkan hal tersebut, sebagai parameter keberhasilan dalam hal pembelajaran dan upaya memotivasi semangat belajar siswa diadakanlah lomba kompetensi siswa sekolah menengah kejuruan (LKS-SMK) tingkat kota Medan [2].

Direktorat Pembinaan Sekolah Menengah Kejuruan, Direktorat Jenderal Pendidikan Dasar dan Menengah, Kementerian Pendidikan dan Kebudayaan menyelenggarakan kegiatan guna memotivasi peningkatan kompetensi siswa berupa kegiatan lomba atau kompetisi tahunan yang

Dikirim : 2019-03-12

Diterima : :2019-03-30

Diterbitkan : 2019-04-01

DOI : https://doi.org/10.29165/komtekinfo.v5i2 
dinamakan Lomba Kompetensi Siswa Sekolah Menengah Kejuruan (LKS-SMK). Kegiatan ini dilakukan sebagai salah satu sarana dan cara untuk mengukur keberhasilan proses pendidikan pada SMK, dan terdiri dari sejumlah kegiatan yang meliputi: Lomba Keterampilan Siswa, Seminar dan Pameran Pendidikan yang semuanya itu diselenggarakan sebagai wahana kompetisi siswa SMK, dan mempromosikan kemampuan siswa SMK kepada dunia usaha dan industri [3].

Dalam sebuah buku yang berjudul Introduction to Information technology menyebutkan bahwa sistem informasi komputer yang mengkombinasikan model dan data dalam memecahkan suatu permasalahan semiterstruktur yang melibatkan user sebagai dukungan kepada pengambil keputusan biasa disebut dengan sistem pendukung keputusan [4].

Dalam proses pengambilan keputusan ada 4 tahapan yang harus dilakukan adalah sebagai berikut [5]

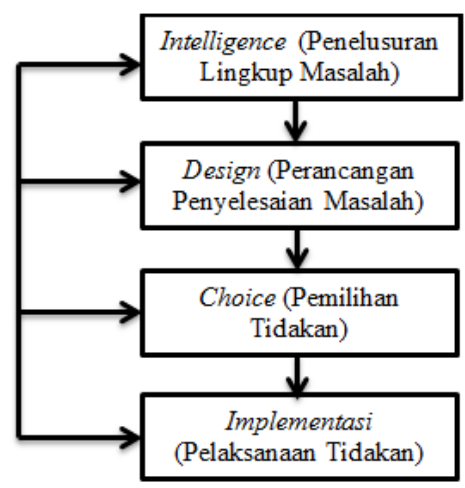

Gambar 1: Tahap Proses Pengambilan Keputusan

Uraian proses setiap bagaian pada Gambar 1 diatas adalah sebagai berikut:

1. Intelligence, tahapan ini mengumpulkan sebanyak mungkin informasi maupun data dari sumber yang ada.

2. Design, tahap ini menganalisa data yang dikumpulkan yang merupakan hasil pemahaman terhadap masalah yang diuji.

3. Pemilihan (Choice Phase), tahapan ini akanmemilih sebuah model, termasuk solusi dari model tersebut. Selanjutnya akan dilakukan sebuah analisis sensitivitas, yaitu dengan merubah beberapa variabel yang ada.

4. Implementasi (Implementation Phase), selanjutnya melakukan melakukan sebuah implementasi dalam sistem DSS.

Banyaknya peluang siswa yang menjadi peserta untuk mengikuti lomba kompetensi siswa disekolah setiap tahunnya sehingga siswa yang akan diikutsertakan ke lomba tidak cukup dengan ranking kelas saja melainkan ada kriteria lain yang harus diperhatikan. Kriteria prestasi akademik, tanggung jawab, kerjasama,disiplin dan jujur. Disamping permasalahan diatas terkadang guru dalam pemilihan siswa mengikuti LKS cenderung bersifat subjektif dan tidak memperhatikan semua faktor diatas sehingga hasil keputusan yang didapat kurang berkualitas dan kurang baik.

Untuk menyelesaikan permasalahan ini digunakanlah sebuah metode Technique For Order Preference By Similarity To Ideal Solution (TOPSIS) agar memudahkan guru dan pihak sekolah untuk menyeleksi siswa yang mengikuti LKS-SMK [6]. Metode TOPSIS ini menggunakan prinsip pada alternatif yang terpilih dan harus mempunyai jarak yang terdekat dari solusi ideal positif dan terjauh dari solusi ideal negatif [7]. Pencapaian jumlah dari keseluruhan nilai terbaik pada setiap atribut disebut solusi ideal positif, sedangkan pencapaian jumlah dari keseluruhan nilai terburuk pada setiap atribut disebut solusi ideal negatif [8]. 
Keunggulan dari metode TOPSIS antara lain: memiliki konsep yang mudah dimengerti dan sederhana, sistem komputerisasi yang efisien, dan memiliki kelebihan dalam mengukur suatu keputusan dari kinerja relatif pada alternatif-alternatif yang ada dalam bentuk matematis sederhana [9]. Oleh karena itu diperlukan sebuah sistem pendukung keputusan untuk memilih peserta yang mengikuti lomba kompetensi siswa agar bisa bermanfaat bagi pihak sekolah [10].

\section{Data dan Metode Penelitian}

Pengumpulan data dilakukan dari beberapa tahap dalam menyelesaikan suatu sistem. Berdasarkan studi pustaka yang ada dan observasi secara langsung, maka data disusun dan dikelompokkan dalam bentuk tabel multikriteria sederhana. Hal ini dilakukan agar mempermudah dalam melakukan analisa data

\subsection{Kerangka Kerja Penelitian}

Kerangka kerja penelitian merupakan tahapan-tahapan sistematis yang dilakukan oleh penulis dalam menyelesaikan penelitian yang berhubungan dengan metode TOPSIS. Adapun kerangka kerja dari penelitian ini dapat dilihat pada Gambar 2.

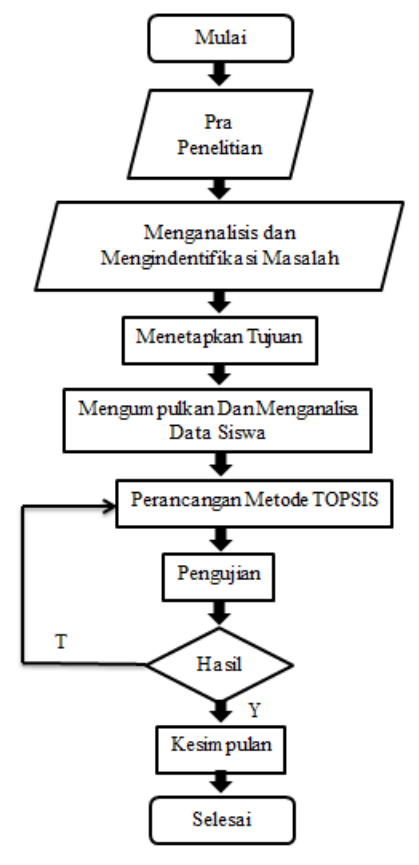

Keterangan :

Gambar 2: Kerangka Kerja Penelitian

1. Pra Penelitian

Penelitian pendahuluan dilakukan dengan survei literatur di jurnal dan perpustakaan.

2. Menganalisis dan Mengidentifikasi Masalah

Dengan menganalisa masalah-masalah yang ada diharapkan dapat secara jelas bagaimana cara mengatasi masalah dengan baik.

3. Menetapkan Tujuan

Tujuan perancangan diperlukan agar penyusunan dalam penelitian ini tidak menyimpang dari tujuan awal dan mendapatkan hasil yang optimal.

4. Mengumpulkan dan Menganalisa Data 
Data-data dikumpulkan berdasarkan pengelompokan yang telah ditentukan. Dalam memperoleh data bisa dilakukan dengan cara:

a. Wawancara dilakukan dengan bertanya langsung kepada narasumber dalam mencari informasi yang dibutuhkan.

b. Pengolahan informasi yang didapatkan baik yang ada di buku, jurnal - jurnal maupun dari situs-situs web yang berkenaan dengan masalah yang diteliti, selanjutnya akan di bandingakan dengan kenyataan yang terjadi dan yang di peroleh penulis di lapangan.

Pada penelitian ini data yang dianalisis adalah data dari SMK Tritech Informatika Medan kelas X RPL 1 dan X RPL 2 tahun ajaran 2017 -2018. Data yang telah didapat nantinya akan diuji mengggunakan metode TOPSIS.

4. Perancangan Metode TOPSIS

Data yang sudah dikumpulkan kemudian diolah menggunakan metode TOPSIS sampai mendapatkan hasil yang bisa dilihat pada Bab berikutnya.

5. Kesimpulan

Pada tahap ini, diambil kesimpulan mengenai apa yang sudah dilakukan dan dicapai selama penetian berlangsung. Kesimpulan harus sesuai dengan tujuan penelitian yang telah ditetapkan pada BAB Pendahuluan.

\section{Hasil dan Diskusi}

Dalam memilih siswa yang mengikuti lomba kompetensi siswa berdasarkan nilai tertinggi, langkah awal yang harus dilakukan adalah menentukan data alternatif. Kemudian menentukan kriteriakriteria yang digunakan.

Tabel 1: Alternatif Siswa Mengikuti Lomba Kompetensi Siswa

\begin{tabular}{|c|c|c|}
\hline KD Alternatif & Alternatif & Keterangan \\
\hline A01 & Siswa A & Fara Nabila Lubis \\
\hline A02 & Siswa B & Boy Hendrawan Lubis \\
\hline A03 & Siswa C & Ummi Hidayah Srg \\
\hline A04 & Siswa D & Afif Jahfal Anwar \\
\hline A05 & Siswa E & M. Irpansyah \\
\hline A06 & Siswa F & Ardika Kuswahyudi \\
\hline A07 & Siswa G & Faturrahman Zulfi \\
\hline A08 & Siswa H & Nona Maulidika \\
\hline A09 & Siswa I & Hamdoko \\
\hline A10 & Siswa J & Dicky Efendi \\
\hline
\end{tabular}

Pada Tabel 1 menjelaskan data alternatif yang dibandingkan untuk mengikuti lomba kompetensi siswa hanya 10 siswa dari ranking 1 sampai 5 yang didapat dari siswa/siswi SMK Tritech Informatika Medan Jurusan RPL 1 dan RPL 2 tahun 2018. Selanjutnya menentukan tingkat kepentingan setiap kriteria.

Tabel 2:Tingkat Kepentingan Setiap Kriteria

\begin{tabular}{|c|c|c|}
\hline Kriteria & Keterangn & Bobot / Kepentingan \\
\hline C1 & Prestasi Akademik & Sangat Tinggi \\
\hline C2 & Tanggung Jawab & Sangat Tinggi \\
\hline C3 & Kerjasama & Sangat Tinggi \\
\hline C4 & Disiplin & Sangat Tinggi \\
\hline C5 & Jujur & Sangat Tinggi \\
\hline
\end{tabular}

Pada Tabel 2 menjelaskan data pembobotan / kepentingan setiap kriteria ditentukan dari pihak Kaprodi RPL SMK Tritech informatika Medan. Bobot setiap kriteria diberikan sebagai berikut: $\mathrm{W}=[$ Sangat Tinggi, Tinggi, Cukup, Rendah dan Sangat Rendah ].

Setiap kriteria diberi bobot oleh pengambil keputusan dengan nilai berupa range anatara 1 sampai 5 seperti: $\mathrm{ST}=5, \mathrm{~T}=4, \mathrm{C}=3, \mathrm{R}=2$ dan $\mathrm{SR}=1$. 


\subsection{Analisis Metode TOPSIS}

Adapun Langkah-langkah Pemilihan siswa mengikuti lomba kompetensi siswa adalah[11][12] :

1. Membuat Matriks Keputusan M.

Dari data yang didapat penulis mengambil 10 data alternatif dari siswa / siswi SMK Tritech Informatika sebagai contoh yang ada pada Tabel 1 dalam perhitungan. Sehingga hasilnya dapat dilihat pada matriks dibawah ini.

$M=\left[\begin{array}{lllll}M_{11} & M_{12} & M_{13} & M_{14} & M_{15} \\ M_{21} & M_{22} & M_{23} & M_{24} & M_{25} \\ M_{31} & M_{32} & M_{33} & M_{34} & M_{35} \\ M_{41} & M_{42} & M_{43} & M_{44} & M_{45} \\ M_{51} & M_{52} & M_{53} & M_{54} & M_{55} \\ M_{61} & M_{62} & M_{63} & M_{64} & M_{65} \\ M_{71} & M_{72} & M_{73} & M_{74} & M_{75} \\ M_{81} & M_{82} & M_{83} & M_{84} & M_{85} \\ M_{91} & M_{92} & M_{93} & M_{94} & M_{95} \\ M_{101} & M_{102} & M_{103} & M_{104} & M_{105}\end{array}\right] \quad M=\left[\begin{array}{lllll}3 & 4 & 3 & 4 & 3 \\ 5 & 5 & 4 & 4 & 4 \\ 3 & 3 & 3 & 3 & 3 \\ 5 & 4 & 4 & 3 & 3 \\ 5 & 4 & 5 & 4 & 3 \\ 4 & 5 & 3 & 3 & 3 \\ 4 & 4 & 4 & 4 & 4 \\ 5 & 4 & 5 & 5 & 4 \\ 4 & 3 & 3 & 3 & 3 \\ 4 & 4 & 3 & 3 & 3\end{array}\right]$

2. Matriks Keputusan Ternormalisasi T.

Setelah matriks keputusan didapat, maka langkah selanjutnya adalah menormalisasikan matriks keputusan dengan persamaan rumus berikut :

$$
\mathrm{t}_{\mathrm{ij}}=\sqrt{\sum_{\mathrm{i}=1}^{\mathrm{m}} \mathrm{M}_{\mathrm{ij}}^{2}}
$$

Dimana : tij adalah elemen dari matriks keputusan yang ternormalisasi.

Mij adalah elemen matriks dari keputusan $\mathrm{M}$.

$\mathrm{i}=1,2,3, \ldots \mathrm{m} ;$ dan $\mathrm{j}=1,2,3, \ldots$ n yang terdiri atas $\mathrm{m}$ alterntif dan $\mathrm{n}$ kriteria.

Mencari nilai pembagi.

$$
\mathrm{M}_{1}=\sqrt{3^{2}+5^{2}+3^{2}+5^{2}+5^{2}+4^{2}+4^{2}+5^{2}+4^{2}+4^{2}}=13.4907
$$

Dengan cara yang sama maka akan diperoleh nilai $\mathrm{M}_{2}, \mathrm{M}_{3}, \mathrm{M}_{4}$ dan $\mathrm{M}_{5}$.

Keterangan :

$\mathrm{M}_{1}=$ penjumlahan nilai alternatif pada kriteria ke-1 dan seterusnya.

Sehingga hasil dari persamaan rumus (1) sebagai berikut :

$$
\mathrm{T}_{11}=\frac{\mathrm{M}_{11}}{\mathrm{M}_{1}}=\frac{3}{13.4907}=0.2224
$$

Dengan cara yang sama maka akan diperoleh nilai $T_{12}, T_{13}, T_{14}$ dan $T_{15}$.

Sehingga hasil yang didapat dari matriks keputusan yang ternormalisasi sebagai berikut:

$$
\mathrm{T}=\left[\begin{array}{lllll}
0.2224 & 0.3123 & 0.2509 & 0.3455 & 0.2847 \\
0.3706 & 0.3904 & 0.3345 & 0.3455 & 0.3797 \\
0.2224 & 0.2343 & 0.2509 & 0.2592 & 0.2847 \\
0.3706 & 0.3123 & 0.3345 & 0.2592 & 0.2847 \\
0.3706 & 0.3123 & 0.4181 & 0.3455 & 0.2847 \\
0.2965 & 0.3904 & 0.2509 & 0.2592 & 0.2847 \\
0.2965 & 0.3123 & 0.3345 & 0.3455 & 0.3797 \\
0.3706 & 0.3123 & 0.4181 & 0.4319 & 0.3797 \\
0.2965 & 0.2343 & 0.2509 & 0.2592 & 0.2847 \\
0.2965 & 0.3123 & 0.2509 & 0.2592 & 0.2847
\end{array}\right]
$$

Keterangan : 
$\mathrm{T}_{11}=$ nilai yang ternormalisasi pada alternatif ke-1 kriteria ke-1 dan seterusnya 3. Membuat matriks normalisasi berbobot $\mathrm{Z}$.

Dengan menggunakan persamaan rumus:

$\mathrm{zij}=w \mathrm{ij} . r i j$

dimana :

$$
\begin{aligned}
& \text { zij adalah elemen dari matriks keputusan yang ternormalisasi terbobot } \mathrm{Z} \text {. } \\
& \text { wij adalah bobot dari kriteria ke-j. } \\
& \text { tij adalah elemen dari matriks keputusan yang ternormalisasi } \mathrm{T} . \\
& \mathrm{T}=\left[\begin{array}{llllll}
0.2224 & 0.3123 & 0.2509 & 0.3455 & 0.2847 \\
0.3706 & 0.3904 & 0.3345 & 0.3455 & 0.3797 \\
0.2224 & 0.2343 & 0.2509 & 0.2592 & 0.2847 \\
0.3706 & 0.3123 & 0.3345 & 0.2592 & 0.2847 \\
0.3706 & 0.3123 & 0.4181 & 0.3455 & 0.2847 \\
0.2965 & 0.3904 & 0.2509 & 0.2592 & 0.2847 \\
0.2965 & 0.3123 & 0.3345 & 0.3455 & 0.3797 \\
0.3706 & 0.3123 & 0.4181 & 0.4319 & 0.3797 \\
0.2965 & 0.2343 & 0.2509 & 0.2592 & 0.2847 \\
0.2965 & 0.3123 & 0.2509 & 0.2592 & 0.2847
\end{array}\right] \text { dikalikan} \quad \mathrm{W}=\left[\begin{array}{lllll}
5 & 5 & 5 & 5 & 5
\end{array}\right] .
\end{aligned}
$$

Sehingga hasil dari persamaan rumus (2) sebagai berikut :

$\mathrm{Z}_{11}=(5)(0.4767)=2.3837$

Dengan cara yang sama maka akan di peroleh nilai $\mathrm{Z}_{12}, \mathrm{Z}_{13}, \mathrm{Z}_{14}, \mathrm{Z}_{15}$.

Keterangan :

$\mathrm{Z}_{11}=$ nilai ternormalisasi terbobot pada alternatif ke-1 kriteria ke-1, matriks keputusan ternormalisasi terbobot diambil dari hasil matriks ternormalisasi $\mathrm{T}$ yang dikalikan dengan masing-masing bobot..

Hasil dari perhitungan tersebut didapat matriks keputusan ternormalisasi terbobot dengan nilai $\mathrm{Z}$ adalah :

$$
\mathrm{Z}=\left[\begin{array}{lllll}
1.1119 & 1.5617 & 1.2544 & 1.7277 & 1.4237 \\
1.8531 & 1.9522 & 1.6725 & 1.7277 & 1.8983 \\
1.1119 & 1.1713 & 1.2544 & 1.2958 & 1.4237 \\
1.8531 & 1.5617 & 1.6725 & 1.2958 & 1.4237 \\
1.8531 & 1.5617 & 2.0906 & 1.7277 & 1.4237 \\
1.4825 & 1.9522 & 1.2544 & 1.2958 & 1.4237 \\
1.4825 & 1.5617 & 1.6725 & 1.7277 & 1.8983 \\
1.8531 & 1.5617 & 2.0906 & 2.1597 & 1.8983 \\
1.4825 & 1.1713 & 1.2544 & 1.2958 & 1.4237 \\
1.4825 & 1.5617 & 1.2544 & 1.2958 & 1.4237
\end{array}\right]
$$

4. Menentukan Solusi Ideal Positif (B+) dan Solusi Ideal Negatif (B-)

Menentukan nilai maksimum dan nilai minimum dari nilai terbobot setiap kriteria sehingga didapat solusi ideal positif dan solusi ideal negatif.

1. Solusi ideal positif $(\mathrm{B}+)$

Untuk matriks solusi ideal positif berdasarkan rumus sebagai berikut:

$Z_{\mathrm{j}}^{+}\left\{\begin{array}{c}\max Z_{\mathrm{ij}} ; \text { jika } \mathrm{j} \text { adalah atribut keuntungan } \\ \text { min } Z_{\mathrm{ij}} ; \mathrm{jika} \mathrm{j} \text { adalah atribut biaya }\end{array}\right\}$

$\mathrm{Z}_{1}^{+}=\max \left(\begin{array}{c}1.1119 ; 1.8531 ; 1.1119 ; 1.8531 ; 1.8531 ; \\ 1.4825 ; 1.4825 ; 1.8531 ; 1.4825 ; 1.4825\end{array}\right)=1.8531$

Dengan cara yang sama maka akan diperoleh $\mathrm{Z}_{2}^{+}, \mathrm{Z}_{3}^{+}, \mathrm{Z}_{4}^{+}, \mathrm{Z}_{5}^{+}$. Sehingga dapat diketahui solusi ideal positif dari matriks ternormalisasi terbobot adalah sebagai berikut:

$\mathrm{B}+=(1.8531 ; 1.9522 ; 2.0906 ; 2.1597 ; 1.8983)$.

Keterangan :

$\mathrm{Z}_{1}+=$ nilai terbesar dari alternatif ke-1 terhadap masing-masing kriteria. 
$\mathrm{B}+=$ seluruh nilai terbesar dari setiap alternatif terhadap masing-masing kriteria.

2. Solusi ideal negatif (B-)

Untuk matriks solusi ideal negatif berdasarkan rumus sebagai berikut:

$Z_{\mathrm{j}}^{-}\left\{\begin{array}{c}\min \mathrm{Z}_{\mathrm{ij}} ; \mathrm{jika} \mathrm{j} \text { adalah atribut keuntungan } \\ \max \mathrm{Z}_{\mathrm{ij}} ; \mathrm{jika} \mathrm{j} \text { adalah atribut biaya }\end{array}\right\}$

$Z_{1}^{-}=\min \left(\begin{array}{c}1.1119 ; 1.8531 ; 1.1119 ; 1.8531 ; 1.8531 ; \\ 1.4825 ; 1.4825 ; 1.8531 ; 1.4825 ; 1.4825\end{array}\right)=1.1119$

Dengan cara yang sama maka akan diperoleh $\mathrm{Z}_{2}^{-}, \mathrm{Z}_{3}^{-}, \mathrm{Z}_{4}^{-}, \mathrm{Z}_{5}^{-}$. Sehingga dapat diketahui solusi ideal negatif dari matriks ternormalisasi terbobot adalah sebagai berikut:

B- $=(1.1119 ; 1.1713 ; 1.2544 ; 1.2958 ; 1.4237)$

Keterangan :

$\mathrm{Z}_{1}^{-}=$nilai terkecil dari alternatif ke-1 terhadap masing-masing kriteria

$\mathrm{B}$ - = seluruh nilai terkecil dari setiap alternatif terhadap masing-masing kriteria.

Dari langkah di atas maka dapat di simpulkan hasil dari matriks solusi ideal positif dan matriks solusi ideal negatif adalah sebagai berikut:

Tabel 3:Hasil Matriks B+ dan B-

\begin{tabular}{|l|l|l|l|l|l|}
\hline B + & 1.8531 & 1.9522 & 2.0906 & 2.1597 & 1.8983 \\
\hline B - & 1.1119 & 1.1713 & 1.2544 & 1.2958 & 1.4237 \\
\hline
\end{tabular}

Tabel 3 merupakan hasil matriks seluruh nilai solusi ideal terbesar dan terkecil dari setiap alternatif terhadap masing-masing kriteria.

5. Menghitung Jarak Solusi Ideal Positif (D+) dan Jarak Solusi Ideal Negatif (D-)

Untuk jarak antara setiap alternatif dengan matriks solusi ideal positif berdasarkan rumus sebagai berikut :

$$
\begin{aligned}
& \mathrm{D}_{\mathrm{i}}^{+=}=\sqrt{\sum_{\mathrm{j}=1}^{\mathrm{n}}\left(\mathrm{z}_{\mathrm{ij}}-\mathrm{z}_{\mathrm{j}}^{+}\right)^{2}, \text { dengan } \mathrm{i}=1,2,3 \ldots \mathrm{n}} \\
& \mathrm{D}_{1}^{+}=\sqrt{\begin{array}{r}
(1.8531-1.1119)^{2}+(1.9522-1.5617)^{2}+(2.0906-1.2544)^{2+} \\
(2.1597-1.7277)^{2}+(1.8983-1.4237)^{2}
\end{array}}=1.3465
\end{aligned}
$$

Dengan cara yang sama maka akan di peroleh nilai untuk $\mathrm{D}_{2}{ }^{+}, \mathrm{D}_{3}{ }^{+}, \mathrm{D}_{4}{ }^{+}, \mathrm{D}_{5}{ }^{+}$sampai $\mathrm{D}_{10}{ }^{+}$.

Keterangan :

D1+ = nilai jarak antara alternatif ke-1 dengan matriks solusi ideal positif.

Untuk jarak antara setiap alternatif dengan matriks solusi ideal negatif berdasarkan rumus sebagai berikut :

$D_{i}^{-}=\sqrt{\sum_{j=1}^{n}\left(z_{i j}-z_{j}^{-}\right)^{2}, \text { dengan } i=1,2,3 \ldots n}$

$\mathrm{D}_{1}=\sqrt{\begin{array}{c}(1.1119-1.1119)^{2}+(1.1713-1.5617)^{2}+(1.2544-1.2544)^{2}+ \\ (1.2958-1.7277)^{2}+(1.4237-1.4237)^{2}\end{array}}=0.5822$

Dengan cara yang sama maka akan di peroleh nilai untuk $\mathrm{D}_{2}{ }^{-}, \mathrm{D}_{3}{ }^{-}, \mathrm{D}_{4}{ }^{-}, \mathrm{D}_{5}{ }^{-}$sampai $\mathrm{D}_{10}{ }^{-}$.

Keterangan :

D1 - = nilai jarak antara alternatif ke-1 dengan matriks solusi ideal negatif.

Tabel 4 : Jarak Solusi Ideal Positif (D+) dan Jarak Solusi Ideal Negatif (D-)

\begin{tabular}{|c|c|}
\hline D+ & D- \\
\hline 1.3465 & 0.5822 \\
\hline 0.6012 & 1.3213 \\
\hline 1.6823 & 0.0000 \\
\hline 1.1396 & 0.9363 \\
\hline 0.7512 & 1.2601 \\
\hline 1.3447 & 0.8644 \\
\hline 0.8070 & 0.9362 \\
\hline
\end{tabular}




\begin{tabular}{|c|c|}
\hline 0.3904 & 1.5404 \\
\hline 1.5550 & 0.3706 \\
\hline 1.4002 & 0.5383 \\
\hline
\end{tabular}

Pada Tabel 4 merupakan hasil matriks jarak solusi ideal positif dan matriks jarak solusi ideal negatif. Dilanjutkan dengan langkah terakhir yaitu :

6. Menentukan nilai preferensi untuk setiap alternatif.

Berdasarkan rumus (7) dan langkah berikut di ambil dari hasil langkah sebelumnya pada Tabel 4.

$\mathrm{V}_{\mathrm{i}}=\frac{\mathrm{D}^{-}}{\mathrm{Di}^{-}+\mathrm{Di}^{+}} \mathrm{i}=1,2, \mathrm{~m}$

$\mathrm{V}_{1}=\frac{0.5822}{1.3465+0.5822}=0.3019$

Selanjutnya dengan cara yang sama V2 sampai dengan V10. Nilai V adalah nilai yang diperoleh antara $\mathrm{D}$ - dan $\mathrm{D}+$ dengan persamaan rumus (7). Hasil perhitungan preferensi pada setiap alternetif dapat dilihat pada Tabel 5.

Hasil akhir perhitungan apabila diperingkatkan sebagai berikut :

Tabel 5 : Tabel Hasil Perangkingan

\begin{tabular}{|c|c|c|}
\hline Rangking & V & Nilai \\
\hline 1 & V8 & 0.7978 \\
\hline 2 & V2 & 0.6873 \\
\hline 3 & V5 & 0.6265 \\
\hline 4 & V7 & 0.5371 \\
\hline 5 & V4 & 0.451 \\
\hline 6 & V6 & 0.3913 \\
\hline 7 & V1 & 0.3019 \\
\hline 8 & V10 & 0.2777 \\
\hline 9 & V9 & 0.1925 \\
\hline 10 & V3 & 0 \\
\hline
\end{tabular}

Dari nilai V pada Tabel 5 dapat dilihat bahwa nilai V6 memiliki nilai terbesar, sehingga dapat disimpulkan bahwa alternatif ke delapan yang akan di pilih. Dengan kata lain siswa H dengan nama Nona Maulidika yang akan di pilih dari data alternatif pada Tabel 1 di atas dengan nilai tertinggi dari beberapa alternatif yang ada.

\subsection{Tampilan Sistem}

Halaman Menu Data Alternatif berfungsi untuk menampilkan data alternatif, Gambar 3.

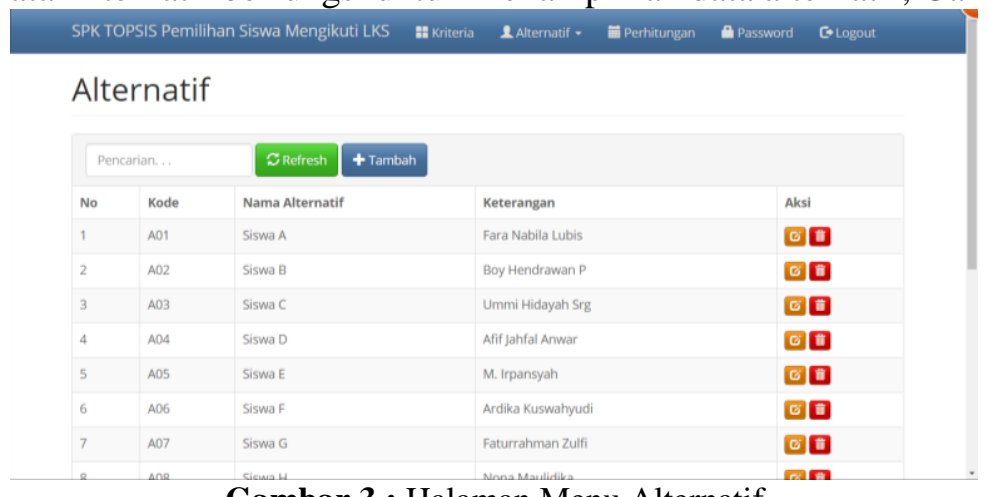

Gambar 3 : Halaman Menu Alternatif

Halaman Menu Data Kriteria berfungsi untuk menampilkan data kriteria, Gambar 4. 


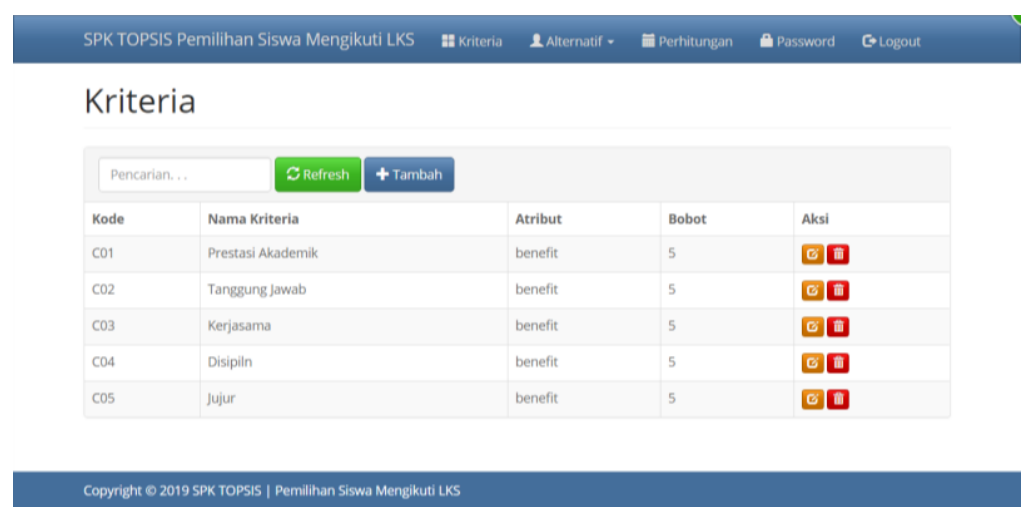

Gambar 4 : Halaman Menu Kriteria

Halaman Menu proses keputusan berfungsi untuk data-data calon peserta mengikuti lomba kompetensi siswa, Gambar 5.

\begin{tabular}{|l|l|l|}
\hline Perangkingan & & Rank \\
\hline \# & Total & 1 \\
\hline A08 - Siswa H & 0.798 & 2 \\
\hline A02 - Siswa B & 0.687 & 3 \\
\hline A05 - Siswa E & 0.627 & 4 \\
\hline A07 - Siswa G & 0.537 & 5 \\
\hline A04 - Siswa D & 0.451 & 6 \\
\hline A06 - Siswa F & 0.391 & 7 \\
\hline A01 - Siswa A & 0.302 & 8 \\
\hline A10 - Siswa J & 0.278 & 9 \\
\hline A09 - Siswa I & 0.192 & 10 \\
\hline A03 - Siswa C & 0 & \\
\hline ECCetak & & \\
\hline
\end{tabular}

\subsection{Analisis Perbandingan}

Gambar 5 : Halaman Perhitungan TOPSIS

Untuk membuktikan kebenaran hasil analisis, perlu adanya pembuktian dari hasil pemilihan siswa mengikuti lomba kompetensi siswa secara manual dengan hasil program. Berikut tahapan proses rekomendasi pemilihan siswa mengikuti lomba kompetensi siswa secara manual sebagai berikut :

1. Pihak Kaprodi meminta data nilai raport kepada bagian tatausaha.

2. Kemudian mengurutkan nama siswa berdasarkan ranking dan rata- rata nilai raport yang didapat.

3. Setelah mendapat siswa yang mengikuti lomba kompetensi siswa didapat berdasarkan ranking dan rata - rata raport, kemudian pihak Kaprodi mengajukan hasil rekomendasinya tersebut kepada Kepala Sekolah.

4. Kemudian Kepala Sekolah menerima hasil rekomendasi dari Kaprodi dan mengesahkan hasil rekomendasi tersebut.

Dari hasil pemilihan siswa mengikuti lomba kompetensi siswa secara manual dan sistem dapat diperoleh hasil yang berbeda untuk tahap urutan perangkingan antara pemilihan secara manual dan pemilihan secara sistem. Berikut perbandingan pemilihan secara manual dan pemilihan secara sistem :

Tabel 6 : Perbandingan Pemilihan Siswa Secara Manual dan Sistem

\begin{tabular}{|c|c|l|c|c|l|l|}
\hline Urutan & $\begin{array}{c}\text { Ranking } \\
\text { Raport }\end{array}$ & \multicolumn{1}{|c|}{ Nama Siswa } & $\begin{array}{c}\text { Rata- } \\
\text { Rata }\end{array}$ & $\begin{array}{c}\text { Ranking } \\
\text { TOPSIS }\end{array}$ & \multicolumn{1}{|c|}{ Nama Siswa } & Nilai V \\
\hline 1 & 1 & Boy Hendrawan P & 89.56 & 1 & Nona Maulidika & 0.7978 \\
\hline 2 & 1 & Nona Maulidika & 88.58 & 2 & Boy Hendrawan P & 0.6873 \\
\hline 3 & 2 & M. Irpansyah & 88.17 & 3 & M. Irpansyah & 0.6265 \\
\hline 4 & 3 & Faturahman Zulfi & 88.01 & 4 & Faturahman Zulfi & 0.5371 \\
\hline
\end{tabular}




\begin{tabular}{|l|l|l|c|c|l|l|}
\hline 5 & 2 & Afif Jahfal Anwar & 87.99 & 5 & Afif Jahfal Anwar & 0.451 \\
\hline 6 & 4 & Ardika Kuswahyudi & 87.86 & 6 & Ardika Kuswahyudi & 0.3913 \\
\hline 7 & 5 & Fara Nabila Lubis & 87.80 & 7 & Fara Nabila Lubis & 0.3019 \\
\hline 8 & 3 & Dicky Effendi & 87.75 & 8 & Dicky Effendi & 0.2777 \\
\hline 9 & 4 & Hamdoko & 87.26 & 9 & Hamdoko & 0.1925 \\
\hline 10 & 5 & Ummi Hidayah Srg & 87.12 & 10 & Ummi Hidayah Srg & 0 \\
\hline
\end{tabular}

Berdasarkan Tabel 6 dapat diamati bahwa hasil pemilihan peserta secara real dengan pemilihan peserta secara sistem terdapat sedikit perbedaan urutan perangkingan dengan kesesuaian sebesar 80\%. Dimana pada pemilihan siswa secara real siswa yang dipilih adalah Boy Hendrawan P dan pada pemilihan secara sistem siswa yang dipilih adalah Nona Maulidika.

\section{Kesimpulan}

Sistem Pengambilan Keputusan Penilaian terhadap pemilihan siswa mengikuti lomba kompetensi siswa merupakan sebuah sistem yang dapat menentukan peserta yang mengikuti lomba kompetensi siswa dari SMK Tritech Informatika Medan yang dalam melakukan pengambilan keputusan dengan menggunakan metode TOPSIS. Dengan adanya sistem ini maka pihak sekolah SMK Tritech Informatika Medan dengan mudah dapat melakukan seleksi peserta yang mengikuti lomba kompetensi siswa sehingga mudah dalam melakukan pemilihan terhadap siswa. Adapun laporan yang dihasilkan dari sistem ini adalah laporan hasil penilaian terhadap pemilihan siswa mengikuti lomba kompetensi siswa dengan beberapa kriteria yaitu prestasi akademik, tanggung jawab, kerjasama, disiplin dan jujur dengan akurasi kesesuaian sebesar $80 \%$..

\section{Referensi}

[1] M. Fatkhurrokhman, Pardjono, "Akuisisi Kompetensi Siswa Pada Kompetensi Keahlian Teknik Instalasi Tenaga Listrik Melalui Praktik Kerja Industri," Jurnal Pendidikan Vokasi, Volume. 6, No 2, 207-218, Juni 2016. http://dx.doi.org/10.21831/jpv.v6i2.9550

[2] M. Widyaningsih, L. Giovani, "Penentuan Peserta Lomba Kompetensi Siswa Menggunakan Simple Additive Weighting (SAW), "Jurnal Informatika dan Komputer (JIKO), Vol. 1, No. 1, Hal : 38-46, Februari 2016. http://dx.doi.org/10.26798/jiko.2016.v1i1.13.

[3] Juknis LKS, 2018

[4] R. Helilintar, W. W. Winarno, H. Al Fatta, " Penerapan Metode SAW dan Fuzzy Dalam Sistem Pendukung Keputusan Penerimaan Beasiswa," Citec Journal, Vol. 3, No.2, 89 - 101, April 2016.

[5] U. Hasanah, G. W. Nurcahyo, J. Santony, "Indikator Pemilihan Jurusan Pada SMK Nusantara Menggunakan Metode SAW,” Jurnal Matik Penusa, Volume. 22, No.1, 39 - 44, Agustus 2018.

[6] H. Agung, Ricky, "Aplikasi Sistem Pendukung Keputusan Untuk Pemilihan Siswa Teladan Menggunakan Metode Topsis”, Jurnal Ilmiah FIFO, Volume VIII, No. 2, 112-126, November 2016. http://dx.doi.org/10.22441/fifo.v8i2.1306.

[7] G. Ginting, Fadlina, Mesran, A. P. U. Siahaan, R. Rahim, "Technical Approach of TOPSIS in Decision Making," IJRTER, Volume. 03, 58 - 64, 2017. https://doi.org/10.23883/ijrter.2017.3388.wpyuj.34899957-1-SM

[8] M. Salim," Sistem Pendukung Keputusan Penerimaan Calon Guru Honor di SMK Gotong Royong Gorontalo Menggunakan Metode Topsis," JURNAL INFORMATIKA UPGRIS Vol. 4, No. 1, 28-33, 2018. http://dx.doi.org/10.26877/jiu.v4i1.2214.

[9] D. Herawatie, E. Wuryanto,"Sistem Pendukung Keputusan Pemilihan Mahasiswa Berprestasi dengan Metode Fuzzy TOPSIS," Journal of Information Systems Engineering and Business Intelligence, Vol. 3, No. 2, 92-100, October 2017. http://dx.doi.org/10.20473/jisebi.3.2.92-100.

[10] A. S. Honggowibowo, "Sistem Pendukung Keputusan Pengadaan Bahan Pustaka Perpustakaan STT Adisutjipto Menggunakan Metode Topsis," Seminar Nasional Teknologi Informasi dan Kedirgantaraan (SENATIK), Vol. II, 101-107, 26 November 2016. http://dx.doi.org/10.28989/senatik.v2i0.36.

[11] C. Surya,'Penilaian Kinerja Dosen Menggunakan Metode TOPSIS (Studi Kasus : AMIK Mitra Guna)," JURNAL RESTI (Rekayasa Sistem dan Teknologi Informasi), Vol. 2, No.1, 322-329, 2018. https://doi.org/10.29207/resti.v2i1.119. 
[12] A. A. Sembiring, A. S. Sembiring, S. R. Siregar, "Sistem Pendukung Keputusan Penentuan Prioritas Pengembangan Industri Kecil Menengah di Kabupaten Karo Menggunakan Metode TOPSIS," Majalah Ilmiah INTI, Volume. 13, Nomor. 2, 2018 